\title{
Advanced Display System for Public Bus Transportation
}

\author{
M Lakshmipathy*, Santosh.B.Panjagal ${ }^{\star *}$, S. Manjula Kumar** \\ ${ }^{\star}$ Assistant Professor, Dept of ECE, Kuppam Engineering College, \\ lakshmipathiece@gmail.com \\ ${ }^{* *}$ Assistant Professor, Dept of ECE, Kuppam Engineering College, \\ santupanjagal@gmail.com \\ ${ }^{* * *}$ M.Tech, Dept of ECE, Kuppam Engineering College
}

\begin{abstract}
The bus arrival time at bus stops in urban traffic environment is highly unpredictable. This is due to random fluctuations in travel demands and interruptions caused by traffic system, incidents, and weather conditions. Providing real-time bus arrival information would enhance the credibility of the public transit system and thus render it more competitive among various other transportation modes. With the emergence of Global Positioning System (GPS) technologies, traffic data collection can be performed more efficiently.
\end{abstract}

In this paper we are implementing The "ADVANCED DISPLAY SYSTEM" to enhance the public transportation system by giving the prior information of the buses arriving towards the bus stop to the people waiting for the bus. It consists of two modules. The first one is In-bus module and second one is Bus stop module. The In-bus module integrates the GPS receiver, GSM Modem, Microcontroller and control switches. This module is mounted to the bus. The Bus stop module is integrated with GSM modem, Microcontroller and LED matrix display. This Bus-Stop module is mounted at the Bus stops. the microcontroller processes the SMS received by the GSM modem and displays it in the LED matrix display. In the LED matrix display the bus number, source, destination station names of the bus, current location name of the bus, the time at which the bus is at the current location, actual time will be displayed.

\section{General Terms}

In Bus Module, Bus Stop Module.

\section{Keywords}

GPS Receiver, GSM Modem \& CAN Transceiver.

\section{Council for Innovative Research}

Peer Review Research Publishing System

Journal: INTERNATIONAL JOURNAL OF COMPUTERS \& TECHNOLOGY

Vol 6, No 1

editor@cirworld.com

www.cirworld.com, member.cirworld.com 


\section{INTRODUCTION}

Mobility is an essential requirement for any type of meaningful involvement in our modern society. Without mobility, an individual's chances for participation in this country's socioeconomic system are severely limited. Since most jobs are not in close proximity to home, the chances of a person attaining gainful employment, without mobility, are slim at best. Furthermore, the lack of mobility can relegate one to a substandard lifestyle. Without some form of adequate transportation, it would not be possible for people to shop, to socialize, to worship, or to participate in many other life enriching activities. For many people, the only possible solution to this problem is public transportation. Since most People have vehicles of their own, they do not realize the important role that public transportation plays in our society.

For many people, especially low-income and welfare dependent families, public transportation is the only source of mobility. The traffic and pollution further emphasizes the importance of public transportation and shows the need for adequate and affordable public transportation for them. However, public transportation services as they currently exist are unable to meet all the demands placed on them. To minimize some of the transportation challenges, the transportation department has begun to apply intelligent transportation System (ITS) technologies.

As the population is growing day by day, one of the major issue people facing is proper transportation facility. Due to the non-availability of the prior information of the buses arrival time, people are using their own vehicles or private vehicles like Motor bikes, auto-rickshaw, taxi etc. Because of these again some problems are their like traffic, air pollution. So the public transportation system should be enhanced. This proposed "ADVANCED DISPLAY SYSTEM" can be used to enhance the public transportation system [1].

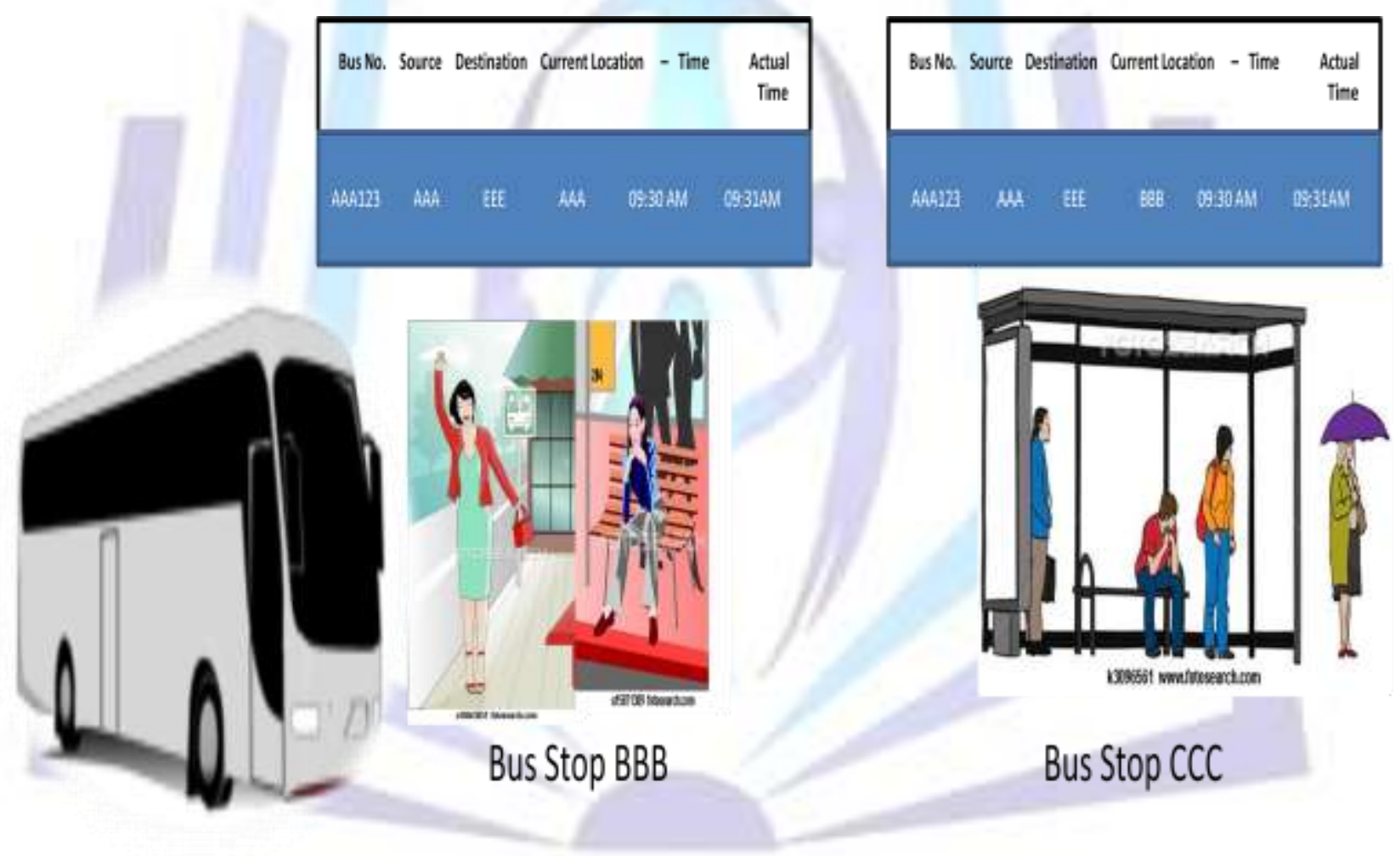

Figure 1: Overview of Bus Display System.

This developed system can be used to give the prior information of the buses arriving towards the bus stop as shown in figure 1. The user at the bus stop can see the bus number, source and destination of the bus, the current bus stop location of the bus with time and the actual time.

\section{SYSTEM DESIGN OVERVIEW}

The "Advanced Display System for Public Bus Transportation" comprises of two modules as shown in the figure 2 below. They are

1. In-bus module

2. Bus stop module.

The In-bus module is installed inside every bus. This In-bus module tracks the buses automatically and sends the SMS to the Bus stop module when the bus reaches the predefined bus stop as shown in the figure 3 and figure 4 . 


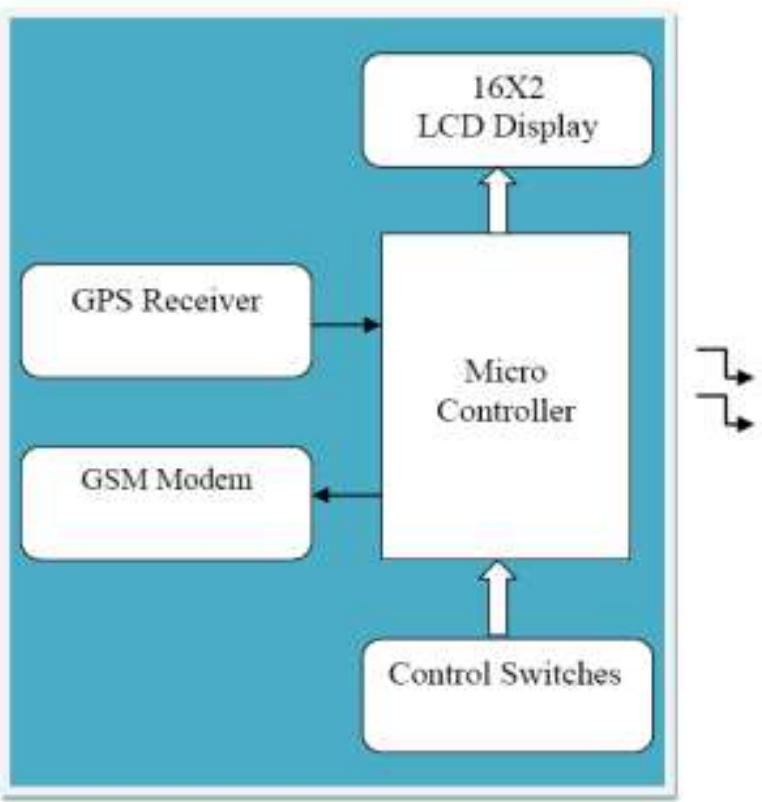

In-bus Module

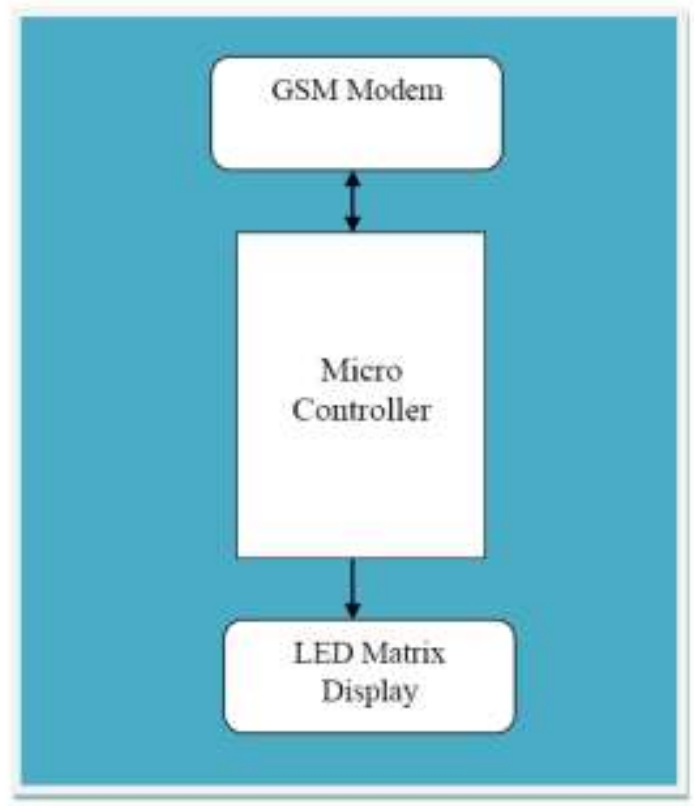

Bus stop Module

Figure 2: Block diagram of Bus Display System

When the bus goes from bus stop ' $A$ ' to bus stop ' $E$ ' the prior information of the bus arrival is given to the next bus stops ' $B$ ' or ' $C$ ' or ' $D$ '.

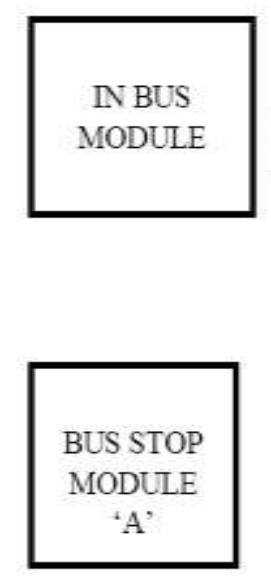

SOURCE
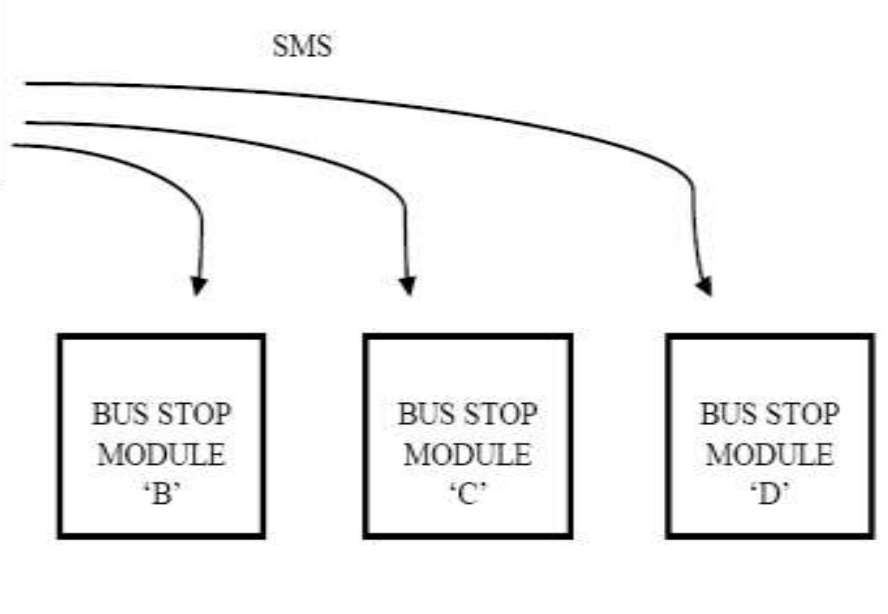

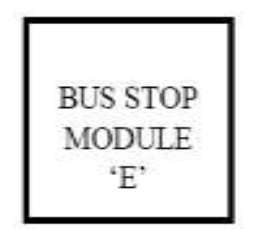

DESTINATION

Figure 3: when bus goes from $A$ to $E$.

Similarly when the bus goes from bus stop ' $E$ ' to ' $A$ ' the prior information of the bus arrival will be given to the next bus stops 'D', 'C', 'B'. 


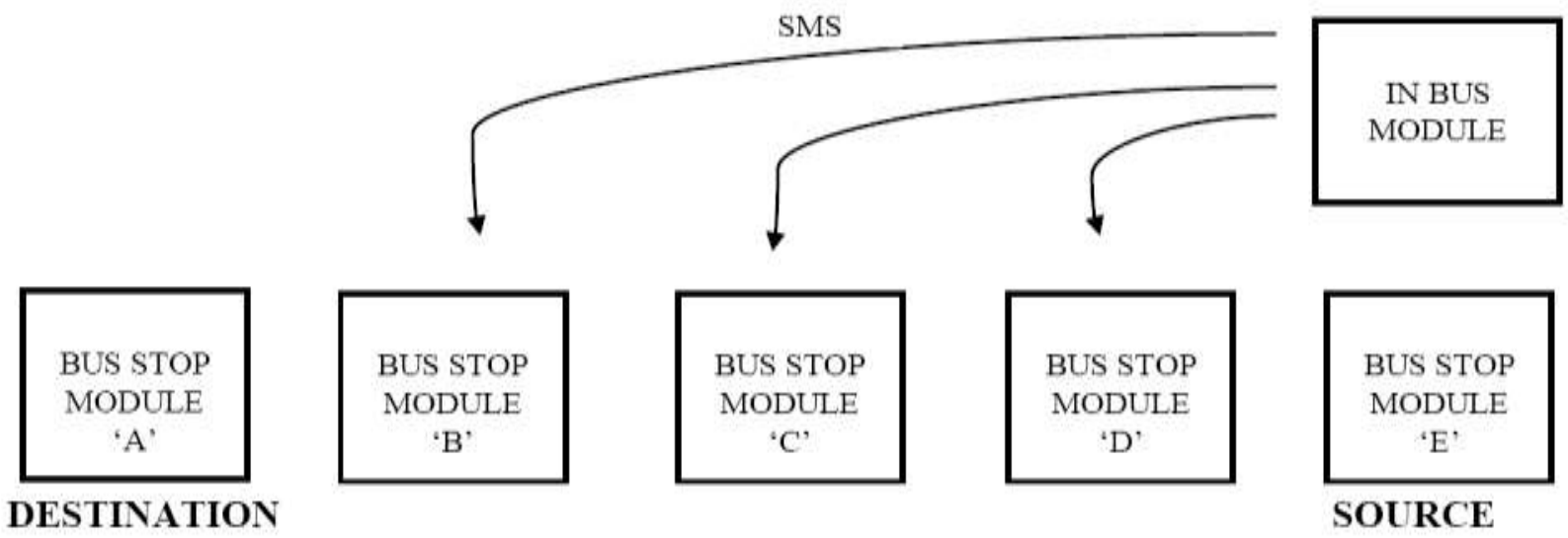

Figure 4: when bus goes from $E$ to $A$.

The direction of sending SMS will be controlled by the user using the control switch at the In-bus module end.

\section{IN-BUS MODULE}

The In-bus module will be installed in the public transportation buses. It tracks the bus in which it is fixed. When the bus reaches the predefined bus stops the timing and route details are sent to the next Bus stop module. This In-bus module comprises the GPS receiver, GSM modem, Control Switches, LCD display, Microcontroller and integrated as shown in the block diagram. The GPS receiver is used to continuously track the bus. Whenever the latitude and longitude values got from the GPS receiver are matches with the bus stop locations (latitude and longitude) which are already loaded by the user, a message will be sent to the next bus stop in the forward direction. The GSM modem is used to send the SMS (Short Message Service) from In-bus module to Bus stop module. This SMS will be in the special format so that the Bus stop module will be able to differentiate the messages from the other sources. The information will be enclosed in the round brackets. The message will have Bus number, Source, Destination, Current location of the bus and IST (Indian Standard Time) at that location.

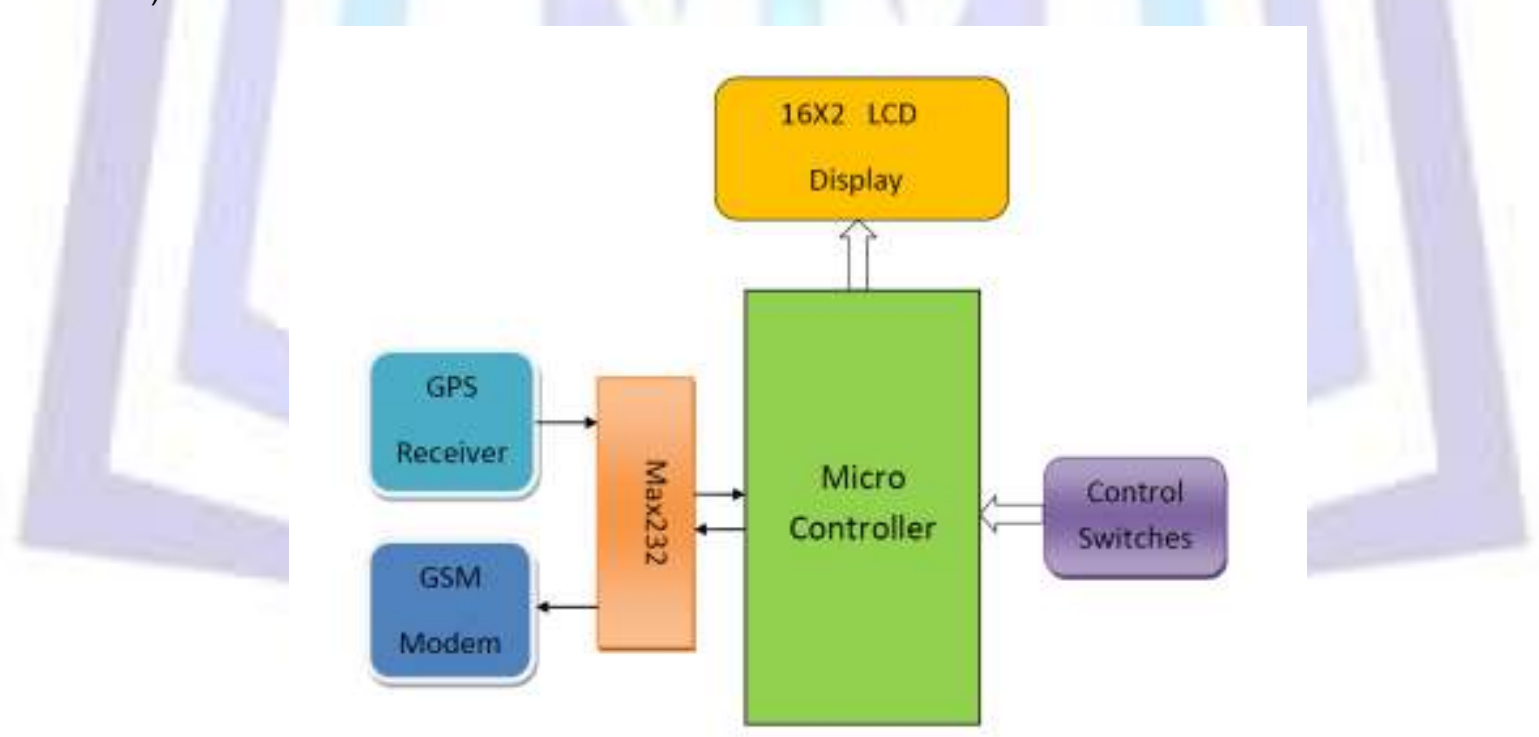

Figure 5: Block Diagram of In-bus Module

The IST is derived from the UTC (Universal Co-ordinate Time) which is available from the NMEA output sentence of the GPS receiver. Two control switches are provided. Among these one switch is used to multiplex the UART receive pin of the microcontroller between GPS receiver data and GUI data. And another switch is used to indicate the direction of the bus travelling-whether source to destination or destination to source. Depending on this switch position only the messages will be sent to the next bus stop. The LCD is used to display the route direction and operation status. Before installing this module into the bus the user has to load the Bus number, Source and Destination station names, all bus stop location (latitude, longitude) details with their names and bus stop ID's (SIM card number) into the module using a specially designed GUI. 


\section{BUS STOP MODULE}

The Bus Stop module will be installed at the bus stops. This module receives the SMS from In-bus module and displays it in the LED matrix display. It comprises of GSM modem, LED matrix display and microcontroller. This module displays the Bus number, Source, Destination, Current location, Time.

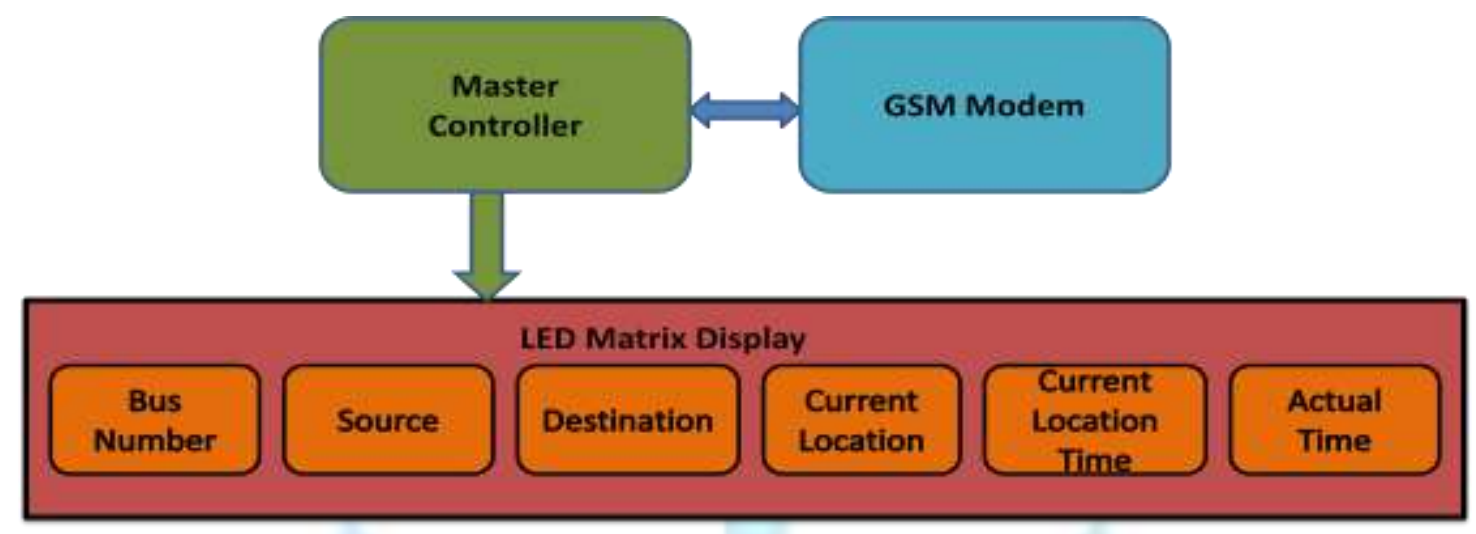

Figure 6: Block Diagram of Bus stop module

\section{A. CAN Transceiver}

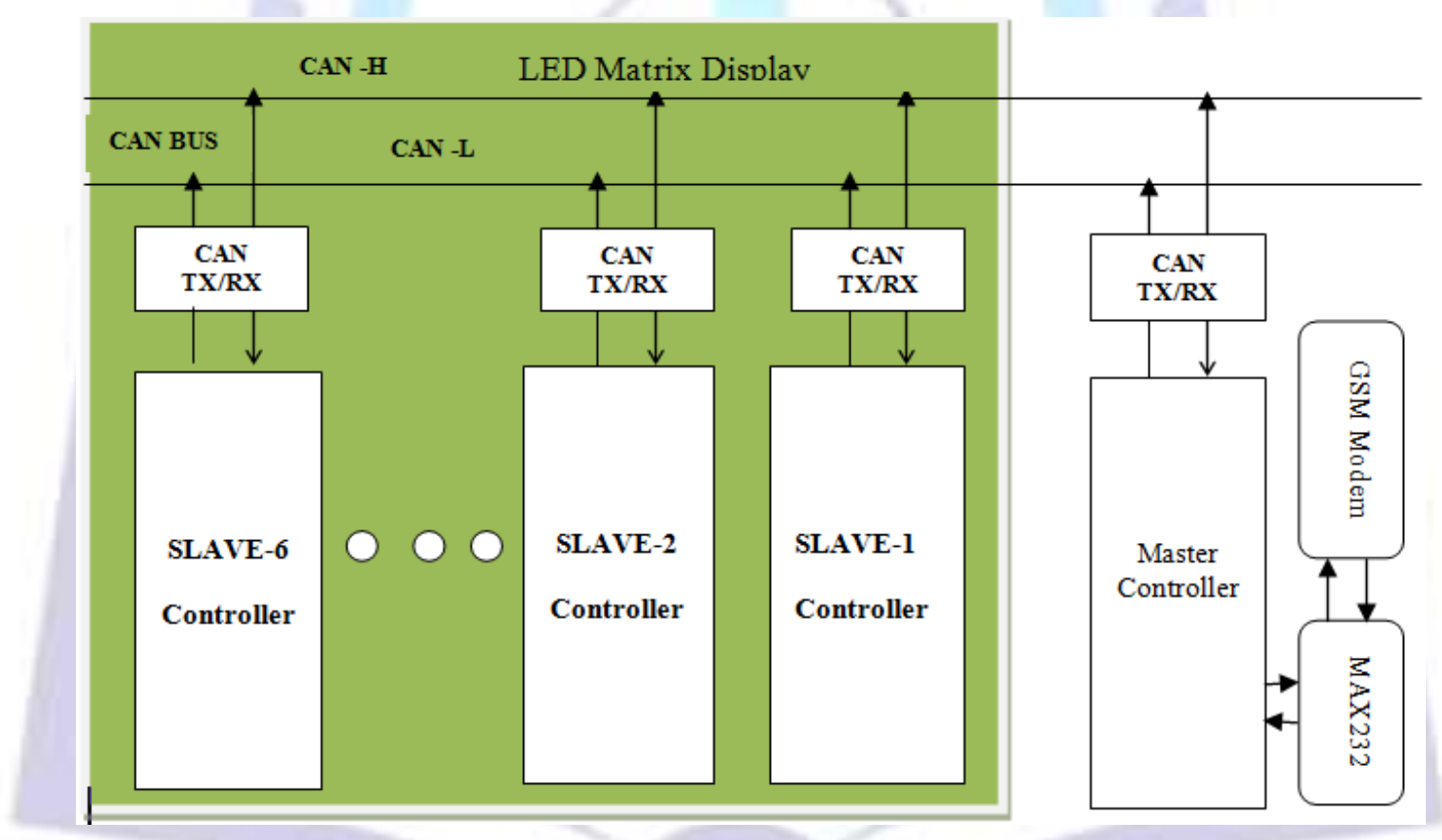

Figure 7: Block Diagram of CAN network interface

Controller Area Network (CAN) is a multicast shared serial bus standard, for connecting electronic control units (ECUs). Controller Area Network (CAN), was originally designed for the automotive industry, but has also become a popular bus in industrial automation as well as other applications. The CAN bus is primarily used in embedded systems, and as its name implies, is the network established among microcontrollers. It is a two-wire, half duplex, high-speed network and is well suited for high speed applications using short messages [9].

Typically; each node in a CAN system must have a device to convert the digital signals generated by a CAN controller to signals suitable for transmission over the bus cabling (differential output). It also provides a buffer between the CAN controller and the high-voltage spikes that can be generated on the CAN bus by outside sources (EMI, ESD, electrical transients, etc.).

The CAN network is built within this Bus stop module in order to send the display message received by the GSM modem to the LED matrix display. And each slave controller displays the received message with the scrolling effect. The following block diagram shows the CAN network connection in the Bus stop module. 


\section{GRAPHICAL USER INTERFACE}

Graphical user interface software is designed using Data Acquisition toolbox in the MATLAB. This graphical user interface is used to upload the bus stop location details like latitude, longitude, corresponding bus stop name and its id number has to be entered into the In-bus module.

\section{SOFTWARE IMPLEMENTATION}

The MPLAB C18 compiler is used for this project for programming all microcontrollers. It is a free-standing, optimizing ANSI C compiler for the PIC18 PIC microcontrollers (MCU). The compiler is a 32-bit Windows console application and is fully compatible with Microchips MPLAB IDE, allowing source-level debugging with the MPLAB ICE incircuit emulator, the MPLAB ICD 2 in-circuit debugger or the MPLAB SIM simulator.

A. Flowcharts
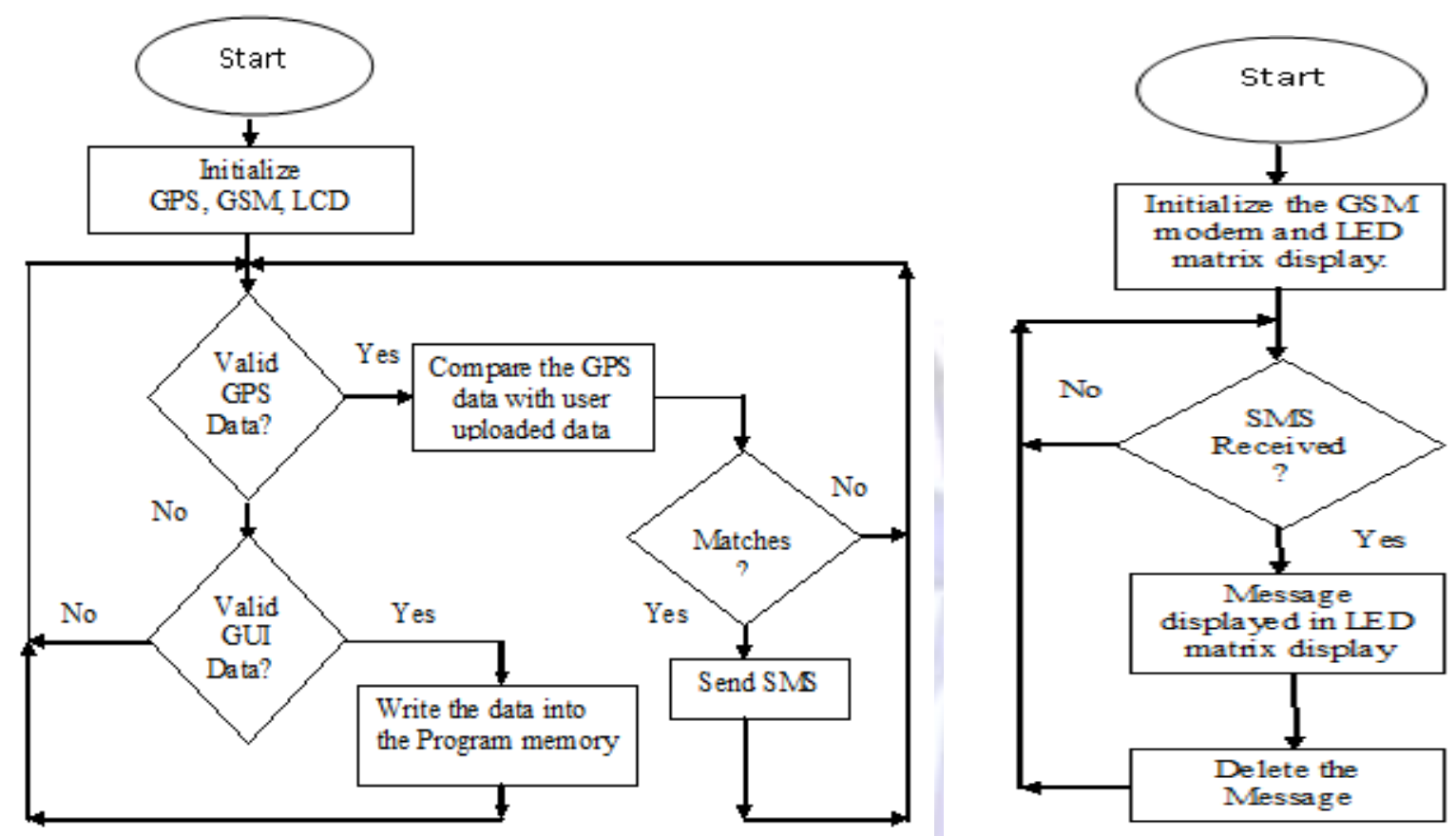

Figure 8: a) In-bus module Flow chart $\quad$ b) Bus-stop module Flow chart

\section{RESULTS AND DISCUSSION}

This project is tested within the NITC, Kerala campus with three different bus stop locations.

Table 1: User uploaded data details

\begin{tabular}{|c|c|c|c|c|c|}
\hline \multicolumn{3}{|c|}{ Bus Number } & \multicolumn{3}{|c|}{ BDS001 } \\
\hline \multicolumn{3}{|c|}{ Source } & \multicolumn{3}{|c|}{ EMBEDDED LAB } \\
\hline \multicolumn{3}{|c|}{ Destination } & \multicolumn{3}{|c|}{ PG-2 } \\
\hline SI No & Latitude & Longitude & Bus stop name & Bus stop ID & Approximate distance \\
\hline 1 & $111933 \mathrm{~N}$ & 075560E & $\begin{array}{c}\text { EMBE-DDED LAB in ECE } \\
\text { Dept }\end{array}$ & 9746887418 & - \\
\hline 2 & $111927 \mathrm{~N}$ & 075560E & ATM Centre In the campus & 9746887418 & 250mts From Bus stop1 \\
\hline 3 & $111918 \mathrm{~N}$ & 075560E & PG-2 Hostel in the campus & 9746887418 & 400mts From Bus Stop2 \\
\hline
\end{tabular}


Consider that a bus with bus number AA123 starts from a source AAA to the destination EEE. BBB, CCC, DDD are the bus stops between AAA and EEE. When the bus reaches BBB bus stop it sends the SMS to the next bus stop CCC. The message format will be as follows "(AA123 AAA EEE DDD 12 30AM)". The UTC time is converted to the local time before sending it to the Bus stop module. The In-bus module is tested with the bus stop location details which are shown in the table 1.

The Bus stop module is tested with the single field LED matrix display. This single field matrix display is able to display up to 28 characters with scrolling effect. So the messages with less than or equal to 28 characters can be displayed. The messages sent to the Bus stop module are displayed in the LED matrix display.

The Bus stop module displays the messages which are enclosed with the round brackets. The message sent by the In-bus module should be in this format "(Bus-Number Source Destination Current-Location Time)". All characters are displayed in the upper case only. The messages received from other sources are discarded.

In main window the welcome screen will be displayed as shown in figure 9. When user clicks on In-bus module button number of bus stops selection window will be opened as shown in figure 10. The user has to select the number of bus stops between the source and destination points. Then the data entry window will be opened as shown in figure 11 . All the bus stop location details has to be entered like latitude, longitude corresponding bus stop name and its bus stop ID.

While designing this GUI proper care has been taken for the type of data entered by the user. For example, the user cannot enter the special characters in the Bus number field. Similarly the user cannot enter the alphabets in the bus stop ID field. A warning message window will be opened when the user enters the wrong data type as shown in figure 12 .

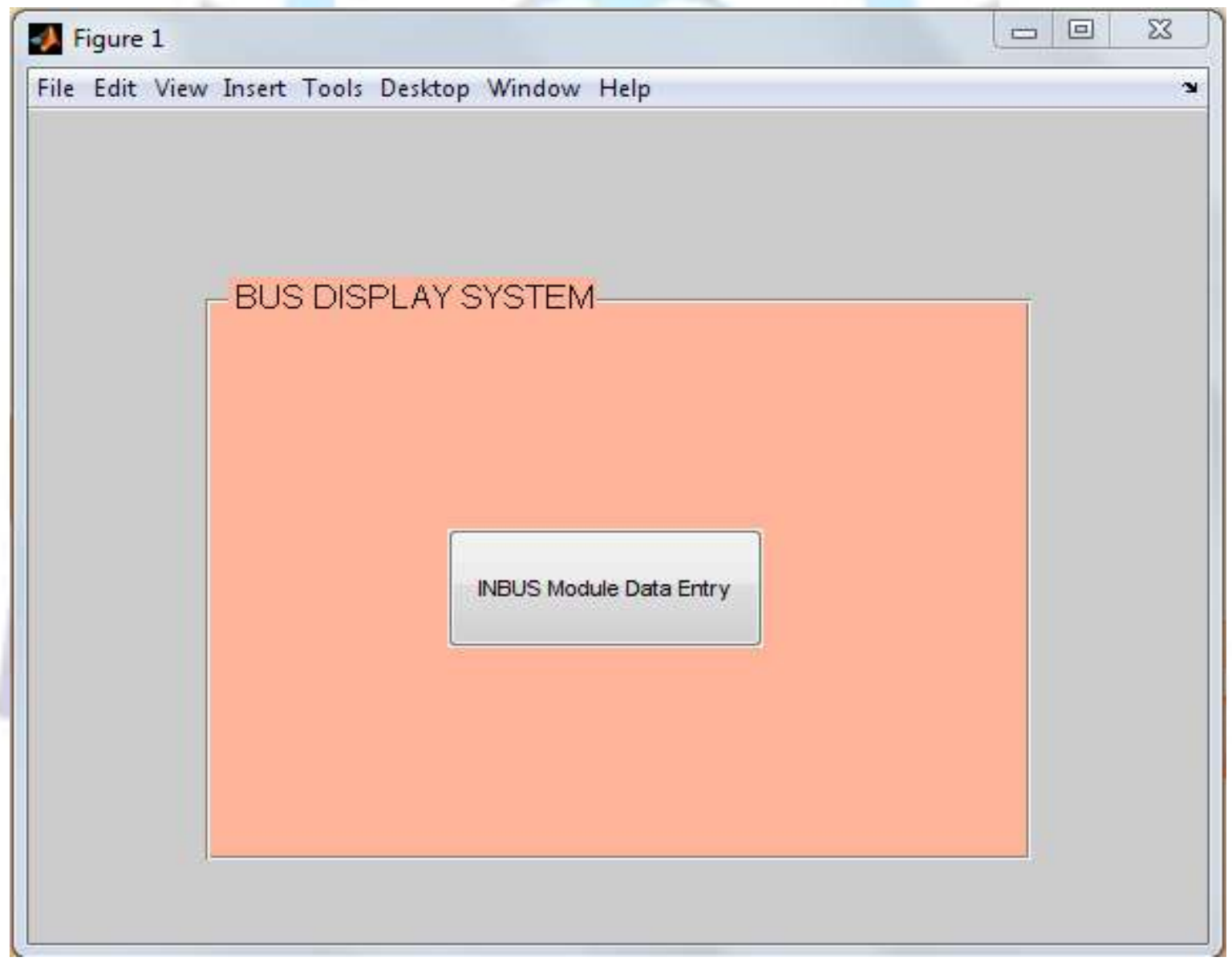

Figure 9: GUI Main windows 


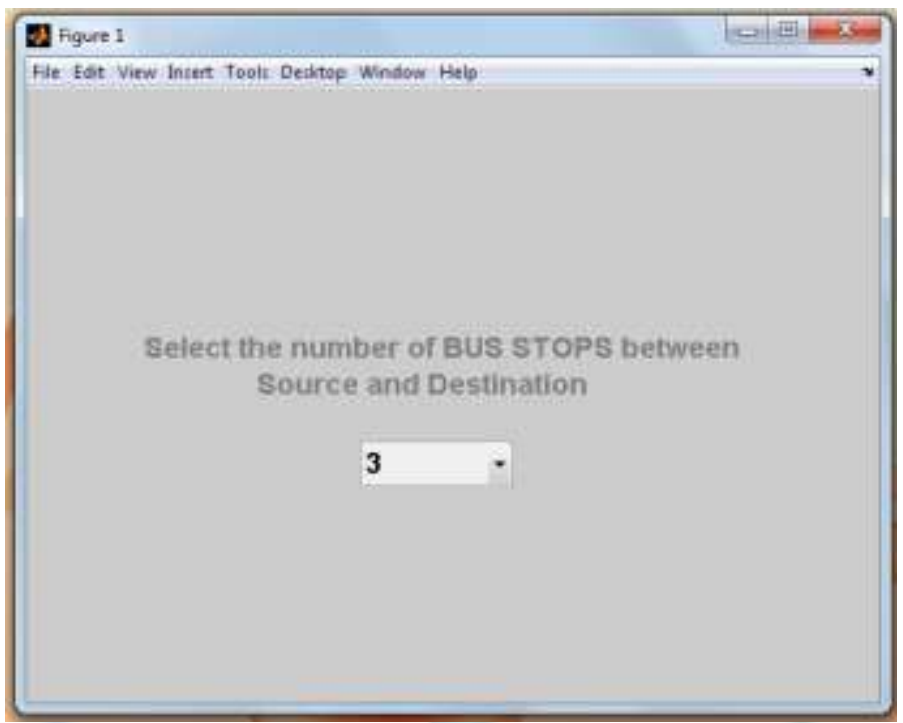

Figure 10: Number of bus stops selection window

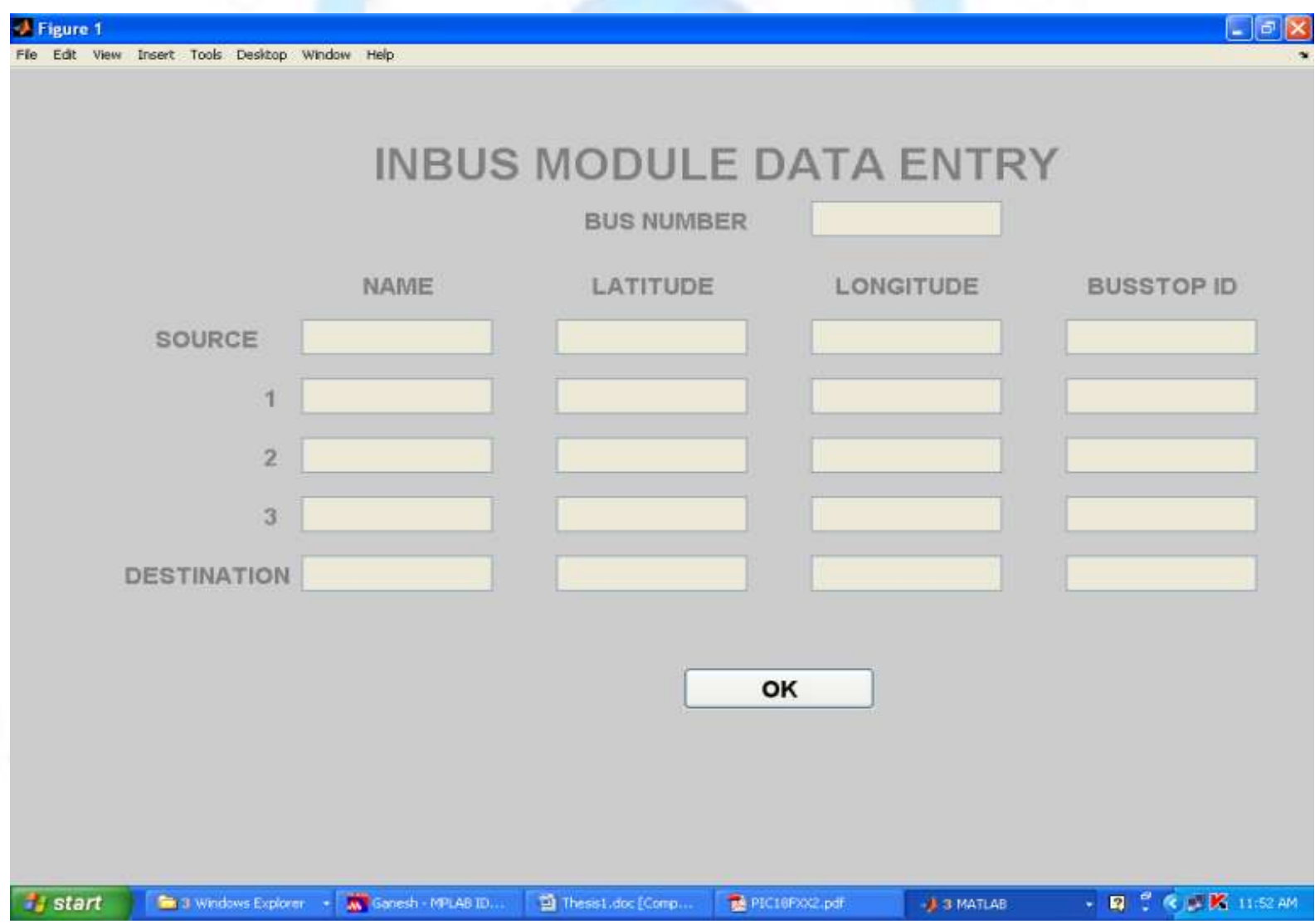

Figure 11: Number of bus stops selection window 


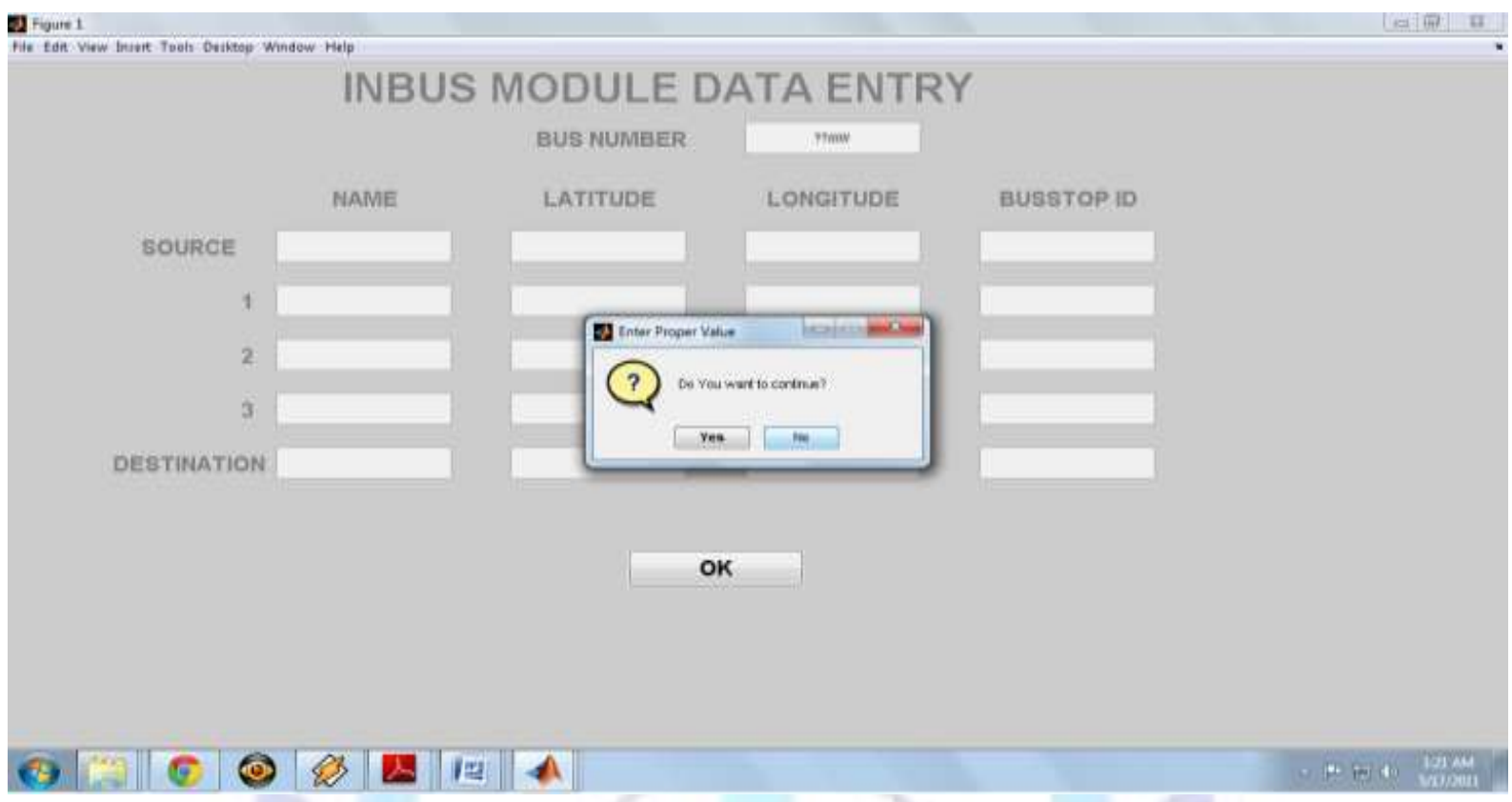

Figure 12: In-bus module data entry window with warning message.

\section{COMPARISON}

In the earlier methods, the prior information of the buses is given either through the public addressing system or printed bus schedule is placed at the bus stops. For this method a dedicated person is needed for bus arrival announcement and it's not effective. By using this proposed method we can give the exact departure time and bus stop location of the bus to the next bus stops. So that the people will use this public transportation effectively.

\section{CONCLUSION AND FUTURE SCOPE}

In this project, a system is developed in which the In-bus module is able to send the bus location information to the Bus stop module. A Graphical user interface is specially designed for the In-bus module to upload the bus stop location details. And the Bus stop module is able to display the message in the LED matrix display. This project has gone through complete system design cycle starting from circuit to system package design. Six field LED matrix display is used in this project to display the prior information of the buses arriving towards the bus stop. From the observation found that, single field LED matrix with maximum 100 character display may used. This reduces the cost and size of the product.

This system can be redesigned in such a way that instead of user uploading the bus stop location details, the Inbus module itself directly acquires the those details directly from the internet using GPRS connection. An automated passenger counting system can be made to cross check the tickets and number of passengers in the bus. An In-bus module can be designed which uploads the bus information directly into the website so that people can know the bus location from anywhere.

\section{REFERENCES}

[1] 1Umar Farooq, 2Tanveer ul Haq, Senior Member IEEE, 3Muhammad Amar, 4Muhammad Usman Asad, 5Asim lqbal "GPS-GSM Integration for Enhancing Public Transportation Management Services", Second International Conference on Computer Engineering and Applications, 2010.

[2] M. A. Mazidi, J. C. Mazidi, R. D. Mckinaly, "The 8051 Microcontroller and Embedded Systems", Pearson Education, 2006.

[3] Muhammad A. Mazidi, Janice Mazidi, Rolin McKinlay, and Paul Ingendorf. "PIC Microcontroller and Embedded Systems". Prentice-Hall, Inc., Upper Saddle River, NJ, USA, 2005.

[4] OrCad PCB design manual.pdf, 2010.

[5]www.rhydolabz.com/documents/gps_gsm/GSM_Modem_RS232_User_Manual.pdf, 2010

[6]www.rhydolabz.com/documents/gps_gsm/MiniGMouse_RS232_UserManual.pdf, 2010.

[7] Available [online]: www.alldatasheet.com, 2010

[8] Available [online]: www.mathworks.com, 2010.

[9] MCP2551 Datasheet, 2010

[10] Available [online]: www.archive.sierrawireless.com/resources/AirPrime/...WMOD2-UserGuide.pdf, 2010. 